\title{
Immunohistochemical Detection of Advanced Glycosylation End Products in Diabetic Tissues Using Monoclonal Antibody to Pyrraline
}

\author{
Satoshi Miyata and Vincent Monnier \\ Institute of Pathology, Case Western Reserve University, Cleveland, Ohio 44106
}

\begin{abstract}
Pyrraline is one of the major Maillard compounds resulting from the reaction of glucose with amino compounds at slightly acidic pH. For in vivo studies, monoclonal pyrraline antibodies were raised after immunization of Balb/c mice with keyhole limpet hemocyamin-caproyl pyrraline conjugate. Of 660 hybridoma clones from one donor, 260 produced an antibody to the free hapten, two of which named Pyr-A and Pyr-B also cross-reacted with L-lysyl pyrraline. Using Pyr-B antibody and an ELISA, a gradual increase in pyrraline immunoreactivity was observed in serum albumin incubated with glucose or 3deoxyglucosone. Plasma pyrraline levels increased fourfold $(P$ $<0.001)$ in Sprague-Dawley rats upon induction of diabetes with streptozotocin and were twofold increased in randomly selected plasmas from diabetic humans. Highly specific pyrraline immunoreactivity was detected in sclerosed glomeruli from diabetic and old normal kidneys as well as in renal arteries with arteriolosclerosis and in perivascular and peritubular sclerosed extracellular matrix and basement membranes. The preferential localization of pyrraline immunoreactivity in the extracellular matrix strengthens the notion that the advanced glycosylation reaction may contribute to decreased turnover and thickening of the extracellular matrix in diabetes and aging. ( $J$. Clin. Invest. 1992. 89:1102-1112.) Key words: nephropathy • extracellular matrix • collagen • Maillard reaction • glycation
\end{abstract}

\section{Introduction}

Nonenzymatic glycosylation (glycation) and the advanced Maillard reaction have been proposed to play a role in the pathogenesis of diabetic complications and in the aging process by forming protein and DNA adducts and cross-links (1). In the case of simple reducing sugars such as aldohexoses, the reaction has been shown in vivo to proceed via the formation of a relatively stable Amadori product (Fig. 1).

Past the stage of the Amadori product the reaction becomes very complex due to the many pathways through which the Amadori product can undergo degradation. Despite this complexity, some progress has been achieved in recent years with structure elucidation of advanced glycosylation end products and Amadori fragmentation products formed in vivo. There is

Address correspondence to Vincent Monnier, Institute of Pathology, Case Western Reserve University, Cleveland, OH 44106. Satoshi Miyata's present address is The Second Department of Internal Medicine, Kobe University School of Medicine, Kobe, 650, Japan.

Received for publication 8 April 1991 and in revised form 14 November 1991.

J. Clin. Invest.

(c) The American Society for Clinical Investigation, Inc.

$0021-9738 / 92 / 04 / 1102 / 11 \$ 2.00$

Volume 89, April 1992, 1102-1112 now unequivocal evidence for the formation of carboxyalkylated proteins during glucose incubation as well as for their presence in aging and diabetic human lens and skin $(2,3)$. Furthermore, our laboratory has recently reported the presence of a fluorescent pentose-derived lysine-arginine protein cross-link named pentosidine in a variety of human tissues rich in extracellular matrix $(4,5)$. Yet other investigators have found evidence for the presence of advanced glycosylation end products of unknown structure in rat and human tissues $(6,7)$.

As part of our efforts to assess the presence of specific advanced glycosylation/Maillard end products in vivo, a few years ago we investigated the structure of the major products resulting from the reaction of glucose with a simple amine under physiological conditions $(8,9)$. The major product extractable into organic solvents was 5-hydroxymethyl-neopentylpyrrole-2-carbaldehyde (neopentyl pyrraline) (8), a compound previously identified in model systems by other Maillard reaction scientists $(10,11)$. Its lability towards acid hydrolysis precluded direct isolation from protein and an immunological assay for its quantitation as a protein hapten was developed. Using rabbit antiserum to caproyl pyrraline immobilized onto poly-L-lysine, we were able to demonstrate that glucose, its Amadori product of lysine, and 3-deoxyglucosone were all precursors of protein-bound pyrraline (12).

Although the polyclonal antibody was helpful for deciphering the mechanism of formation of pyrraline, high levels of nonspecific staining made it useless for the assessment of immunoreactivity specific to pyrraline in tissue sections. To circumvent this problem, we developed monoclonal antibodies to immobilized caproyl pyrraline in mice. Below we describe their production, characterization, and ability to recognize glucoseand diabetes-modified molecules, and we provide the first immunohistochemical demonstration of advanced Maillard/glycosylation products in tissue sections from humans who died of diabetic complications or old age.

\section{Methods}

Chemical synthesis of pyrraline derivatives. The syntheses of caproyl pyrraline, butyl, propyl, L-lysyl, and neopentyl pyrralines were previously described (12).

Synthesis of 3-deoxyglucosone (3-DG).' 3-DG was prepared essentially according to the method of Khadem as described before (13).

Coupling of caproyl pyrraline onto keyhole limpet hemocyanin $(K L H)$. Caproyl pyrraline was coupled onto KLH using the carbodiimide coupling reaction enhanced by $N$-hydroxysulfosuccinimide (14). KLH (7.0 mg; Calbiochem Corp., La Jolla, CA; $M_{\mathrm{r}}=3,000,000$ $7,500,000)$ and caproyl pyrraline $(7.4 \mathrm{mg}$ ) were dissolved in $500 \mu \mathrm{l}$ of water (HPLC grade; Fisher Scientific Co., Pittsburgh, PA). To this solution were quickly added $1.4 \mathrm{mg}$. of $N$-hydroxysulfosuccinimide

1. Abbreviations used in this paper: ACA, amino caproic acid; DAB, diaminobenzidine; KLH, keyhole limpet hemocyanin; NGS, normal goat serum; TBS, Tris-buffered saline; 3-DG, 3-deoxyglucosone. 

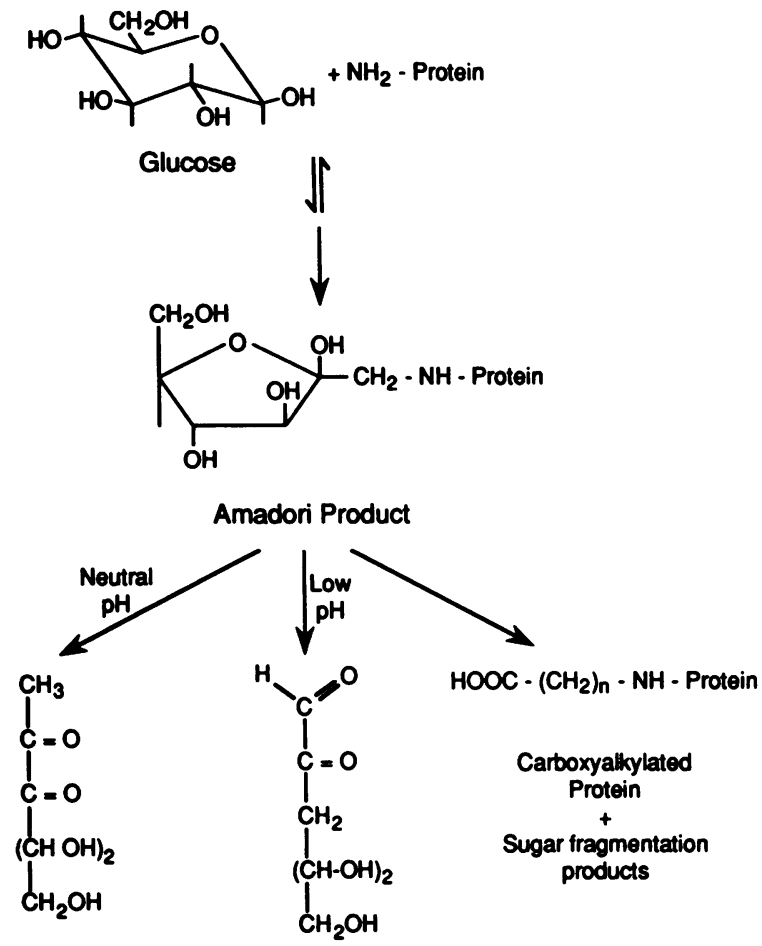

1 -deoxyglucosone 3 -deoxyglucosone

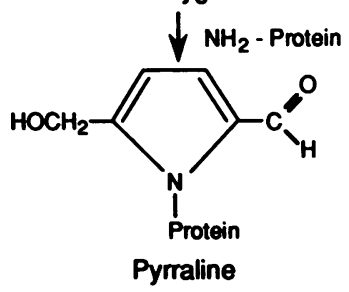

Figure 1. Reaction pathway leading to the formation of pyrraline from glucose. The formation of 1-deoxyglucosone, carboxyalkylated proteins, and sugar fragmentation products illustrates some of the products known to result from the degradation of Amadori products.

(Pierce Chemical Co., Rockford, IL) in $150 \mu \mathrm{l}$ of water and $42.3 \mathrm{mg}$ of 1-cyclohexyl-3-(2-morpholinoethyl)-carbodiimide metho-p-tolunenesulfonate (Sigma Chemical Co., St. Louis, MO) in $350 \mu$ l of water. After $5 \mathrm{~min}$ at room temperature, the solution was transferred to a dialysis tubing $\left(M_{\mathrm{r}}\right.$ cutoff 2,000, Spectrapor No. 6; Spectrum Medical Ind., Los Angeles, CA) and dialyzed twice against 3 liters of PBS, pH 7.4, for 24 $h$. A portion of the dialyzed protein was solubilized by digestion with pronase $\mathrm{E}$ to quantitate the amount of pyrraline incorporated into the protein. Using specific absorbance at $296 \mathrm{~nm}$, it could be estimated that approximately 1 of 5 lysine residues had been modified.

Coupling of caproyl pyrraline onto BSA as a coating reagent for the ELISA. $7 \mathrm{mg}$ of fatty acid-free and globulin-free BSA, (N. A-0281; Sigma) and $1.5 \mathrm{mg}$ of caproyl pyrraline were dissolved in $500 \mu \mathrm{l}$ of water (HPLC grade). To this mixture were added $1.4 \mathrm{mg}$ of $\mathrm{N}$-hydroxysulfosuccinimide (Pierce Chemical Co.) in $150 \mu \mathrm{l}$ of water, quickly followed by $42.3 \mathrm{mg}$ of 1-cyclohexyl-3-(2-morpholinoethyl)-carbodiimide metho-p-toluenesulfonate (Sigma) in $350 \mu \mathrm{l}$ of water. After 8 min of reaction at room temperature, the resulting solution was dialyzed against 3 liters of PBS as described above. Absence of free hapten in the BSA conjugate was confirmed by TLC $(1: 2$, hexane/ethyl acetate, detected by 2,4-dinitrophenylhydrazine reagent). The molar ratio of BSA: hapten was 1:24 based on the ultraviolet spectra and the molar absorption coefficient of caproyl pyrraline (12).

Immunization procedure. Balb/c mice were used for immunization. $200 \mu \mathrm{g}$ of immunogen was dissolved in $200 \mu \mathrm{l}$ of PBS at pH 7.4. The solution was emulsified with $200 \mu$ l of Freund's complete adjuvant
(Sigma) and injected into mice intraperitoneally. $3 \mathrm{wk}$ later, the mice were boosted by intraperitoneal injection with $100 \mu \mathrm{g}$ of immunogen in $200 \mu \mathrm{l}$ of PBS emulsified with $200 \mu \mathrm{l}$ of Freund's incomplete adjuvant followed by two additional boosting injections every 2 wk. Blood was collected from the tail vein before each immunization. Antiserum titer was determined by ELISA as mentioned below. The mouse with the best antiserum titer was selected and injected with $200 \mu \mathrm{g}$ of immunogen in $400 \mu \mathrm{l}$ of PBS without adjuvant intravenously $3 \mathrm{~d}$ before killing for fusion.

Enzyme-linked immunoassay. $100 \mu \mathrm{l}$ of BSA conjugated with caproyl pyrraline $(0.25 \mu \mathrm{g} / \mathrm{ml}$ PBS) was dispensed into each well of a microliter plate as coating reagent and incubated for an hour at $37^{\circ} \mathrm{C}$ in a moist chamber. After washing the plate three times with PBS, $200 \mu \mathrm{l}$ of $1 \%$ ovalbumin (grade V; Sigma) were applied into each well and incubated for an hour at room temperature in the moist chamber to block remaining active sites on the plastic phase. The plate was washed once with $0.1 \%$ ovalbumin in PBS. $50 \mu$ l of mouse serum or culture supernatant to be tested was then applied into each well and incubated for an hour at room temperature under shaking. After washing three times with $0.1 \%$ ovalbumin solution, $50 \mu \mathrm{l}$ of the 1,000 times-diluted goat anti-mouse IgG conjugated with alkaline phosphatase (Boehringer Mannheim Corp., Indianapolis, IN) in 1\% ovalbumin solution was added to each well and incubated for an hour at room temperature under shaking. After three washings with $0.1 \%$ ovalbumin solution, $100 \mu \mathrm{l}$ of $p$-nitrophenyl phosphate (Sigma) substrate solution $(1 \mathrm{mg} / \mathrm{ml})$ was added and the plate was incubated under mild shaking. The absorbance at $410 \mathrm{~nm}$ was measured by enzyme immunoassay reader (model MR700; Dynatech Laboratories, Inc., Chantilly, VA) using $490 \mathrm{~nm}$ as reference wavelength.

Characterization of pyrraline antibodies and quantitation of protein-bound pyrraline by ELISA. Positive antisera, culture supernatants, and purified antibodies were checked for specific binding of the free hapten by preincubation with 200 pmol caproyl pyrraline for $3 \mathrm{~h}$ at $37^{\circ} \mathrm{C}$ before incubation with the ELISA plate coated with BSA-pyrraline. A similar preincubation period was used for determination of cross-reactivity with pyrraline analogues, except that each compound was tested over a range of concentrations varying from $20 \mathrm{fmol}$ to 2,000 nmol. For preincubations with protein and plasma samples, protein concentrations varied from 100 to $250 \mu \mathrm{l}$ per well.

Preparation of monoclonal antibodies. Hybridomas secreting monoclonal antibodies to pyrraline were produced using the method of Schulman et al. (15) as modified by Kaetzel (16). Spleen cells from the immunized mouse were fused with mouse myeloma cells of the SP 2/0 cell line at the cell ratio of 5:1. The cells were cultured with Hypoxanthine-Aminopterin-thymidine-supplemented RPMI 1640 medium to obtain selective growth of hybrid cells in the 96-well tissue culture plates containing a "feeder" suspension of normal Balb/c mouse spleen cells. When colonies of cloned hybridomas became visible, culture supernatants were tested for the presence of monoclonal antibody against caproyl pyrraline by ELISA as described above. Positive clones were expanded and tested for cross-reactivity against L-lysyl pyrraline by ELISA. Two clones that were found to secrete antibody recognizing L-lysyl pyrraline were subcloned twice by limiting dilution method. The subcloned hybridoma cells were expanded by intraperitoneal injection into $\mathrm{Balb} / \mathrm{c}$ mice that had been previously primed by intraperitoneal injection of $0.5 \mathrm{ml}$ of 2,6,10,14-tetramethylpentadecane (pristane). Ascites fluid was collected after $\sim 10 \mathrm{~d}$ and purified with protein A-Sepharose column.

Incubation of human serum albumin with glucose or 3-deoxyglucosone. Defatted human serum albumin (A-1887; Sigma) was dissolved in PBS at pH 5.4 and 7.4 at a concentration of $100 \mathrm{mg} / \mathrm{ml}$ as a stock solution. A solution with a glucose concentration of $0,5,50$, and 500 $\mathrm{mM}$, and a protein concentration of $50 \mathrm{mg} / \mathrm{ml}$ was prepared from $1 \mathrm{M}$ glucose solution in PBS at pH 5.4 or 7.4 at the appropriate ratio. Similar solutions containing 0,5 , and $50 \mathrm{mM}$ of 3-DG at pH 5.4 and 7.4 were prepared. The solutions were sterilized by filtration through $0.2-$ $\mu \mathrm{m}$ pore membrane (Acrodisc 4182; Gelman Sciences Inc., Ann Arbor, MI) into sterile conical tubes and incubated at $37^{\circ} \mathrm{C}$ in the dark. Ali- 
quots of $1 \mathrm{ml}$ were withdrawn on day $0,6,12,20$, and 30 using a sterile pipette and stored at $-80^{\circ} \mathrm{C}$ until assayed. Before ELISA, samples were dialyzed at $4^{\circ} \mathrm{C}$ for $48 \mathrm{~h}$ three times against 3 liters of PBS (pH 7.4). After dialysis, all samples were equalized with PBS to a final protein concentration of $24 \mathrm{mg} / \mathrm{ml}$ using the protein assay kit (Bio-Rad Laboratories, Richmond, CA).

Incubation of $\epsilon$-amino caproic acid (ACA) with glucose. $\mathrm{\epsilon}$-ACA was incubated with 5,50 , and $500 \mathrm{mM}$ glucose solution. The final concentration of $\epsilon$-ACA was adjusted to $5.9 \mathrm{mg} / \mathrm{ml}$ in PBS (pH 5.4 and 7.4), such that the number of $\epsilon$-amino groups per milliter solution was identical with that contained in $1 \mathrm{ml}$ of $50 \mathrm{mg} / \mathrm{ml} \mathrm{HSA}$ solution assuming 59 L-lysyl residues per mole HSA. The incubation was done under sterile conditions as described above. Aliquots were taken on day 0,6 , 12,20 , and 30 and frozen at $-80^{\circ} \mathrm{C}$ until assayed for caproyl pyrraline by ELISA.

Ninhydrin treatment to lysyl pyrraline. $200 \mu 1$ of $40 \mathrm{mM}$ lysyl pyrraline was treated with $100 \mu \mathrm{l} 10 \mathrm{mM}$ ninhydrin in ethylalcohol/acetic acid, pH 5.0, for $10 \mathrm{~min}$ at $65^{\circ} \mathrm{C}$. Alanine at a concentration of $20 \mathrm{mM}$ in PBS was then added and incubated for additional $10 \mathrm{~min}$. The reaction mixture was evaporated to dryness and reconstituted in $200 \mu \mathrm{l}$ PBS. ELISA was performed using $0.02-2,000$ pmol deaminated lysyl pyrraline (i.e., "norlysyl pyrraline") as described above.

Preparation of diabetic rat plasma. 20 Sprague-Dawley female rats (200-220 g) were used for evaluation of pyrraline formation in experimental diabetes. 12 rats were injected with streptozotocin $(65 \mathrm{mg} / \mathrm{kg}$ body wt; The Upjohn Co., Kalamazoo, MI). Presence of diabetes was confirmed the next day by determination of glucosuria using Chemstrip 56 (Boehringer Mannheim Diagnostics, Inc.). Eight other rats were injected with $0.1 \mathrm{M}$ citrate buffer ( $\mathrm{pH} \mathrm{4.5)}$ as control. Blood was taken from the tail vein with heparinized syringe before and 2, 4, 7, 10, and 13 weeks after the injection. Plasma was separated by centrifugation (Microfuge; Beckman Instruments, Inc., Palo Alto, CA) and stored frozen until assayed. Plasma protein values were assessed using the protein assay kit (Bio-Rad) and adjusted to $5 \mathrm{mg} / \mathrm{ml}$ with PBS (pH 7.4) for pyrraline assay by ELISA. Red blood cells were processed for determination of glycohemoglobin by boronate affinity chromatography using the Glyco Gel B kit from Pierce Chemical Co.

Human plasma. 20 plasma specimens from diabetic individuals and 10 age-matched control plasmas were obtained through the Clinical Chemistry Laboratory at the University Hospitals of Cleveland. Mean glycohemoglobin values were $11.7 \pm 2.9 \%$ (SD) and $5.3 \pm 1.0 \%$, respectively. Plasma protein values were adjusted to $5 \mathrm{mg} / \mathrm{ml}$ using the protein assay (Bio-Rad) for subsequent quantitation of pyrraline by ELISA.

Autopsy subjects. Formalin-fixed and paraffin-embedded tissue blocks were obtained from the permanent storage facility of the Division of Anatomic Pathology at our Institute. Tissues were obtained from young (three), middle-aged (three), and elderly individuals (three) without diabetes, and from two middle-aged type I diabetic subjects who died of moderate to severe complications. Tissues studied included kidney, lung, skin, brain, pancreas, heart, aorta, and tracheal cartilage. Typical findings are presented below.

Immunohistochemical method. Immunohistochemical detection of pyrraline was performed with the peroxidase-antiperoxidase staining method for paraffin-embeddedd tissue currently in use at the Institute's Immunocytochemistry Laboratory. 3- $\mu \mathrm{m}$ tissue sections in triplicate on the same slide were deparaffinized by treatment for twice $5 \mathrm{~min}$ with xylene, followed by a 3-min wash each absolute, $95 \%$ and $70 \%$ ethanol. Slides were then placed for 30 min in methanol containing $30 \% \mathrm{H}_{2} \mathrm{O}_{2}$, rinsed twice in distilled water, and placed in a container of $1 \%$ Trisbuffered saline (TBS) and normal goat serum (NGS) until further use. Slides were placed in a humidity chamber and overlaid with TBS-10\% NGS for 10 min and incubated overnight with a 1:100 dilution of PyrB antibody. For blocking experiments, a 3-hr preincubation period of antibody with free hapten was carried out before application to the tissue section. The following morning, excess antibody solution was drained off and the slide was washed three times with $1 \%$ TBS-NGS and dried. The slide was incubated with the second antibody, biotiny- lated horse anti-mouse IgG (Vector Labs, Inc., Burlingame, CA) for 15 min, rinsed with TBS-NGS, dried, and incubated for $30 \mathrm{~min}$ at room temperature with avidin biotinylated horseradish peroxidase $\mathrm{H}$ reagent (Vectastain, Elite ABC kits; Vector Labs). A final wash of $0.05 \mathrm{M}$ Tris $\mathrm{HCl}$ at $\mathrm{pH} 7.6$ was performed.

The color reaction was carried out by incubating the slide with freshly prepared 3,3-diaminobenzidine (DAB) reagent until staining was complete. This reagent was prepared by mixing $0.5 \mathrm{ml}$ frozenthawed stock DAB reagent with freshly added $5 \mu \mathrm{l}$ of $30 \% \mathrm{H}_{2} \mathrm{O}_{2}$ followed by $4.5 \mathrm{ml}$ of $0.05 \mathrm{M}$ TrisHCl, pH 7.6. The DAB stock reagent consists of $50 \mathrm{mg}$ of DAB in $6.7 \mathrm{ml}$ of Tris buffer. The reaction was stopped by placing the slide in water. Fixation was performed for $1 \mathrm{~min}$ in $0.5 \% \mathrm{OsO}_{4}$ followed by a wash in water. The slides were counterstained with hematoxylin.

\section{Results}

Production of antipyrraline antibodies in mice. The formation of pyrraline antibodies in two mice that responded to the KLHimmunogen is shown in Fig. 2. The titers were determined by ELISA and the mouse with the highest titer at 6 wk (mouse 1) was selected for the production of hybridomas. 260 clones out of 660 secreted antibody against the hapten caproyl pyrraline. All clones were further tested for their ability to recognize L-lysyl pyrraline. Two clones, 9A3 and $10 \mathrm{C} 11$, were found to crossreact with L-lysyl pyrraline and were therefore expanded. These clones were renamed Pyr-A and Pyr-B, respectively. Their antibodies were typed by immunodiffusion in agarose gels and found to belong to the class IgG $2 a$.

Pyr-A and Pyr-B clones were implanted into mouse peritoneum and purified antibodies were obtained after protein-A column chromatography as described above.

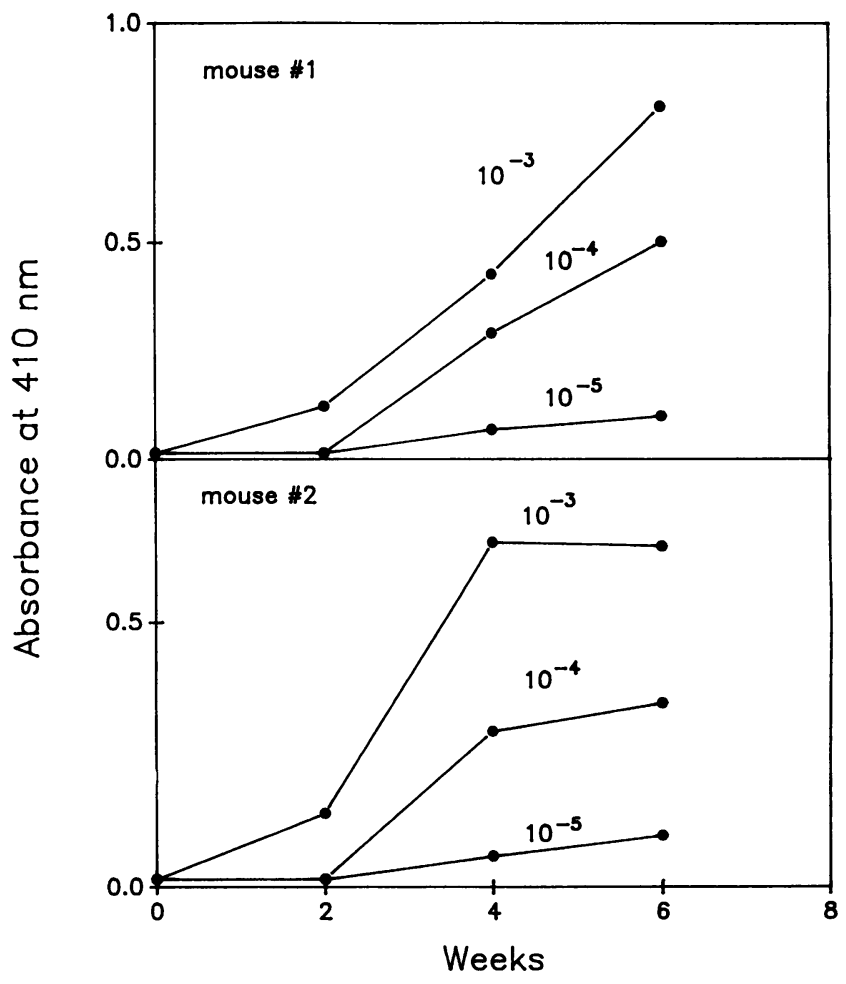

Figure 2. Serum anti-caproyl pyrraline antibody titer at different dilutions in Balb/c mice immunized with caproyl pyrraline-KLH conjugate. 


\begin{tabular}{|c|c|c|c|c|c|c|}
\hline \multirow[b]{2}{*}{ Compound } & & \multirow[b]{2}{*}{ Structure } & \multicolumn{2}{|c|}{ Concentration* } & \multicolumn{2}{|c|}{ Cross-reactivity* } \\
\hline & & & Pyr.A & Руг.B & Pyr.A & Pyr.B \\
\hline & & \multicolumn{5}{|c|}{ (pmol/well) } \\
\hline$\epsilon$-Caproyl- & & $\mathrm{R}=-\left(\mathrm{CH}_{2}\right)_{5} \mathrm{COOH}$ & 1.4 & 1.2 & $100 \%$ & $100 \%$ \\
\hline Butyl- & & $\mathrm{R}=-\left(\mathrm{CH}_{2}\right)_{3} \mathrm{CH}_{3}$ & 0.4 & 0.25 & $350 \%$ & $480 \%$ \\
\hline Propyl- & $\mathrm{HOH}_{2} \mathrm{C} \quad \mathrm{R} \quad \mathrm{CHO}$ & $\mathrm{R}=-\left(\mathrm{CH}_{2}\right)_{2} \mathrm{CH}_{3}$ & 3.0 & 0.6 & $46.7 \%$ & $200 \%$ \\
\hline$\epsilon$-Lysyl- & PYRRALINE & 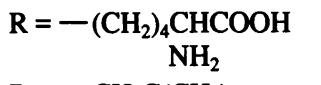 & $1,700.00$ & 500.00 & $0.08 \%$ & $0.24 \%$ \\
\hline Neopentyl- & & $\mathrm{R}=-\mathrm{CH}_{2} \mathrm{C}\left(\mathrm{CH}_{3}\right)_{3}$ & ND & $1,300.00$ & ND & $0.09 \%$ \\
\hline Neopentyl glycosyl pyrrole & $\mathbf{R}_{1}$ & $\begin{aligned} \mathrm{R}_{1}= & -\mathrm{CH}_{2} \mathrm{C}\left(\mathrm{CH}_{3}\right)_{3} \\
\mathrm{R}_{2}= & -\mathrm{CHO} \\
\mathrm{R}_{3}= & -\mathrm{CH}(\mathrm{OH}) \mathrm{CH}(\mathrm{OH}) \\
& -\mathrm{CH}_{2} \mathrm{OH}\end{aligned}$ & ND & ND & ND & ND \\
\hline Pyrrole & & $\mathbf{R}_{1}=\mathbf{H}, \mathbf{R}_{2}=\mathrm{H}, \mathbf{R}_{3}=\mathbf{H}$ & ND & ND & ND & ND \\
\hline Pyrrole-2-carboxy-aldehyde & & $\begin{array}{l}\mathbf{R}_{1}=\mathrm{H}, \mathrm{R}_{2}=-\mathrm{CHO} \\
\mathbf{R}_{\mathbf{3}}=\mathbf{H}\end{array}$ & ND & ND & ND & ND \\
\hline 5-Hydroxy-methylfurfural & & & ND & ND & ND & ND \\
\hline$\epsilon$-fructosyl-L-Lysine & & & ND & ND & ND & ND \\
\hline L-Lysine & & & ND & ND & ND & ND \\
\hline Caproic acid & & & ND & ND & ND & ND \\
\hline
\end{tabular}

Each compound was tested separately at $20 \mathrm{fmol}-2 \mathrm{nmol} /$ well under the standard assay conditions.

* At $50 \%$ inhibition of binding.

ND, not detectable

Characterization of monoclonal Pyr-A and Pyr-B antibodies by ELISA. The details of the characterization of Pyr-A and Pyr-B are summarized in Table I. Reactivity with caproyl pyrraline, the free hapten, was defined as $100 \%$. Both antibodies cross-reacted with higher affinity with butyl pyrraline than caproyl pyrraline (350\% and $480 \%$, respectively), suggesting that the absence of the carboxyl group in the free hapten increases the antibody affinity. On the contrary, the presence of the amino group in L-lysyl pyrraline decreased the cross-reactivity and $500 \mathrm{pmol} /$ well was necessary to obtain $50 \%$ inhibition of binding in the case of Pyr-B (Fig. 3). However, when the amino group of L-lysyl pyrraline was removed by ninhydrin

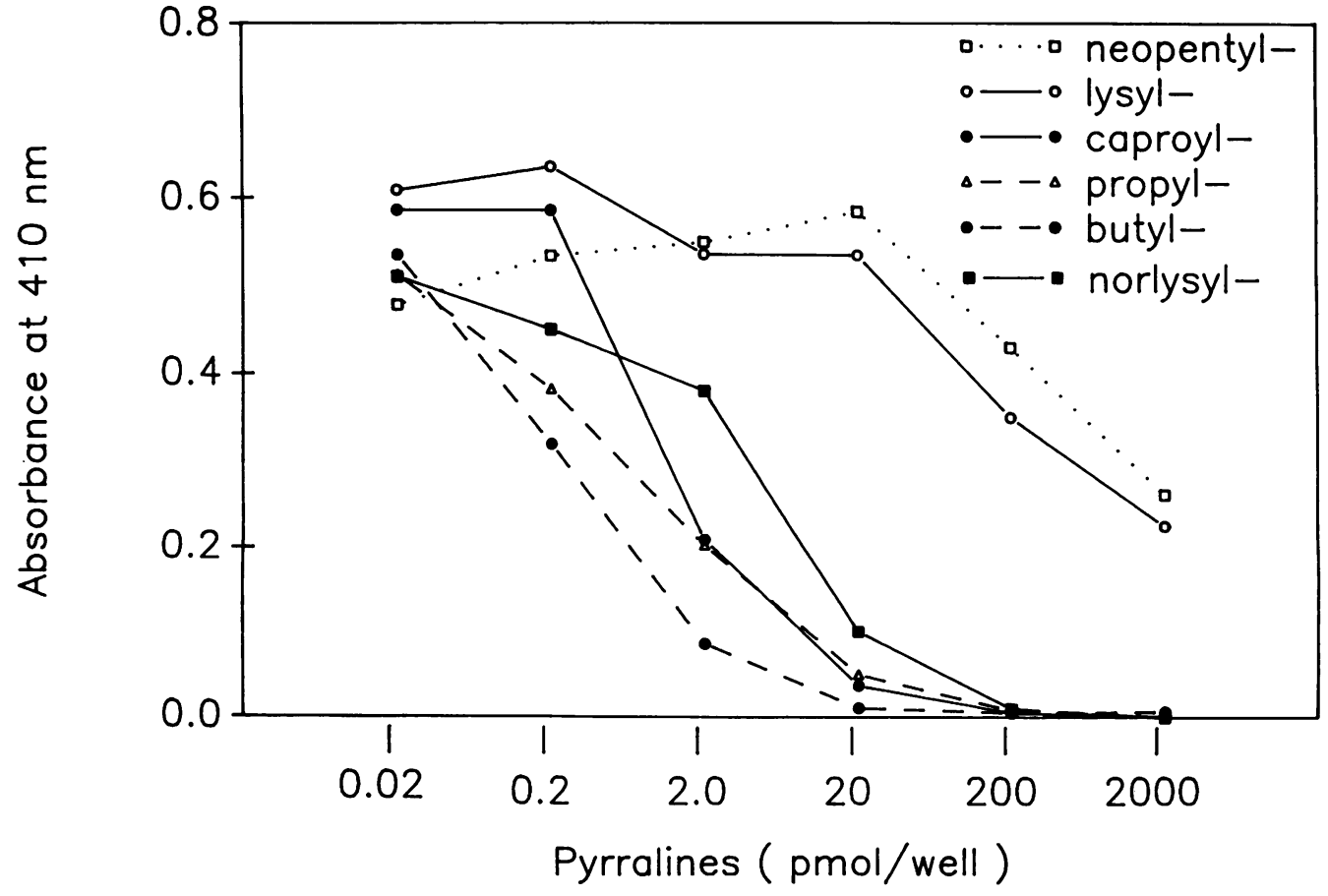

Figure 3. ELISA of pyrraline analogues tested with monoclonal Pyr-B antibody. The curves represent the ability of each analogue to inhibit binding of the monoclonal antibody to immobilized caproyl pyrraline-BSA conjugate. 
treatment, the cross-reactivity of deaminated lysyl pyrraline (norlysyl pyrraline) increased from $0.24 \%$ to $15 \%$ (Fig. 3). Further characterization of Pyr-A and Pyr-B revealed that Pyr-B was still able to recognize the sterically unfavorable neopentyl pyrraline, albeit at much higher concentrations. No cross-reactivity was seen with $\epsilon$-amino caproic acid, L-lysine, and $\epsilon$-fructosyl-L-lysine, suggesting that these residues in native proteins or tissue sections would not lead to nonspecific interactions. Furthermore, other unsubstituted pyrroles or end products of the Maillard reaction, such as neopentyl glycosyl pyrrole (9), were not recognized. The higher affinity of Pyr-B versus Pyr-A towards L-lysyl pyrraline led us to choose the former antibody for probing the advanced Maillard reaction in model systems and in proteins exposed to glucose in vitro and in vivo.

Formation of pyrraline in serum albumin and $\mathrm{\epsilon}$-amino caproic acid incubated with glucose and 3-deoxy-glucosone. Previous observations from our and other laboratories suggested that 3-DG is the immediate precursor to pyrraline and that the reaction is catalyzed at lower $\mathrm{pH}(12)$. Overall similar results were obtained for human serum albumin incubated with 5 and $50 \mathrm{mM}$ 3-DG in PBS (Fig. 4, top and center panels). The levels of pyrraline that were reached after $30 \mathrm{~d}$ of incubation at $37^{\circ} \mathrm{C}$ with $50 \mathrm{mM}$ 3-DG were three times higher at pH 5.4 (i.e., 2,400

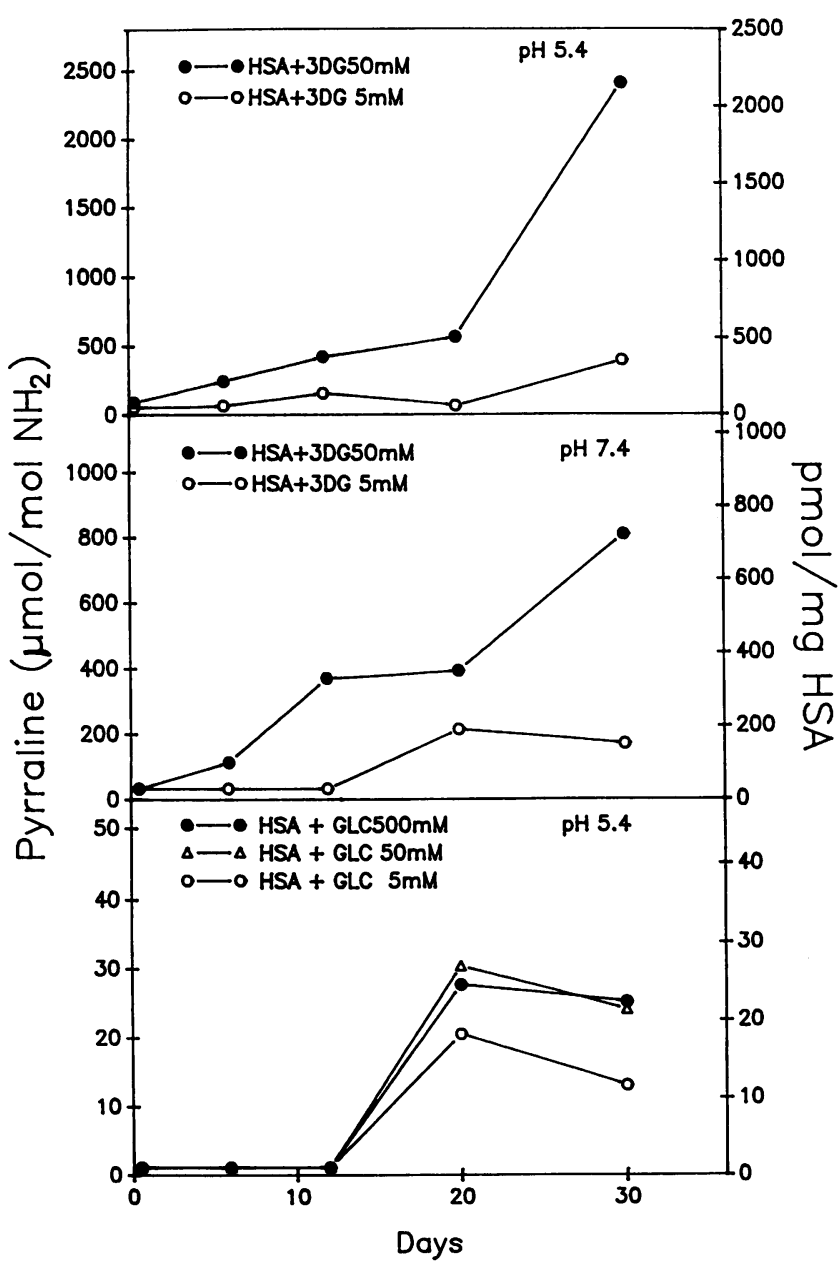

Figure 4. Quantitation of pyrraline by ELISA in HSA incubated at $37^{\circ} \mathrm{C}$ in PBS with 3-deoxyglucosone and glucose at various $\mathrm{pH}$ and concentrations. The protein concentration was $50 \mathrm{mg} / \mathrm{ml}$. The ELISA was standardized with L-lysyl pyrraline.

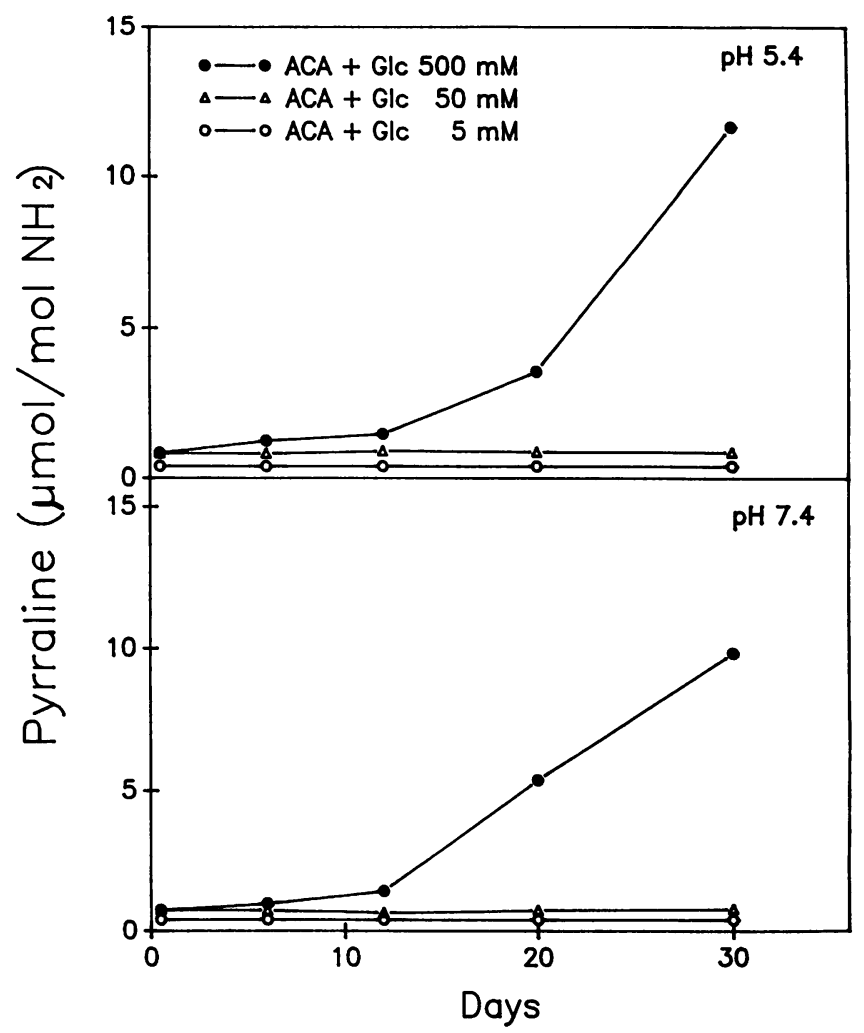

Figure 5. Quantitation of pyrraline in incubations of $\epsilon$-amino caproic with glucose under identical conditions as described in Fig. 4. The concentration of $\epsilon$-amino caproic acid was adjusted to $45 \mathrm{mM}$ to reflect the concentration of free $\epsilon$-amino groups of lysyl residues contained in $50 \mathrm{mg} \mathrm{HSA} / \mathrm{ml}$. The ELISA was standardized with caproyl pyrraline to allow comparison of absolute amounts.

$\mathrm{pmol} / \mathrm{mg} \mathrm{HSA}$ ) than at pH 7.4 (i.e., $800 \mathrm{pmol} / \mathrm{mg} \mathrm{HSA}$ ) and 5-10 times lower at $5 \mathrm{mM}$ 3-DG.

The incubation of human serum albumin at $\mathrm{pH} 5.4$ with glucose at three different concentrations revealed a lag period of approximately 10 days consistent with the necessity of forming Amadori products before 3-deoxyglucosone from which pyrraline is derived (Fig. 4, bottom panel). When the reaction was carried out at pH 7.4, no HSA-bound pyrraline was detected (not shown). The reason why no pyrraline was detected at $\mathrm{pH} 7.4$ and why a stronger relationship with glucose concentration was not observed at pH 5.4 appears to relate to the formation of side products on the protein which mask the antigen accessibility. This was confirmed by incubating under identical conditions $\epsilon$-amino caproic acid with glucose using concentrations of $\mathrm{NH}_{2}$-groups that were identical with those of HSA. Under these conditions, pyrraline formed at $500 \mathrm{mM}$ glucose both at pH 5.4 and 7.4, and the overall pyrraline concentration at $30 \mathrm{~d}$ was in the same range as that observed at $\mathrm{pH}$ 5.4 with HSA (Fig. 5). In a parallel experiment (not shown), we incubated Sepharose-lysine at $37^{\circ} \mathrm{C}$ with $500 \mathrm{mM}$ glucose at pH 5.4 and 7.4 for a few days. At pH 7.4, the amount of glucose incorporated was $150 \%\left(\mathrm{~mol} / \mathrm{mol} \mathrm{per} \mathrm{NH}_{2}\right)$ whereas it reached only $50 \%$ at $\mathrm{pH}$ 5.4. This strongly suggests that diglycosyl adducts known to form in larger quantities at pH 7.4 may have masked antigen accessibility. Taken together, these results show and suggest that glucose-derived pyrraline does form under physiological conditions and can be detected in proteins provided the epitope is accessible. 


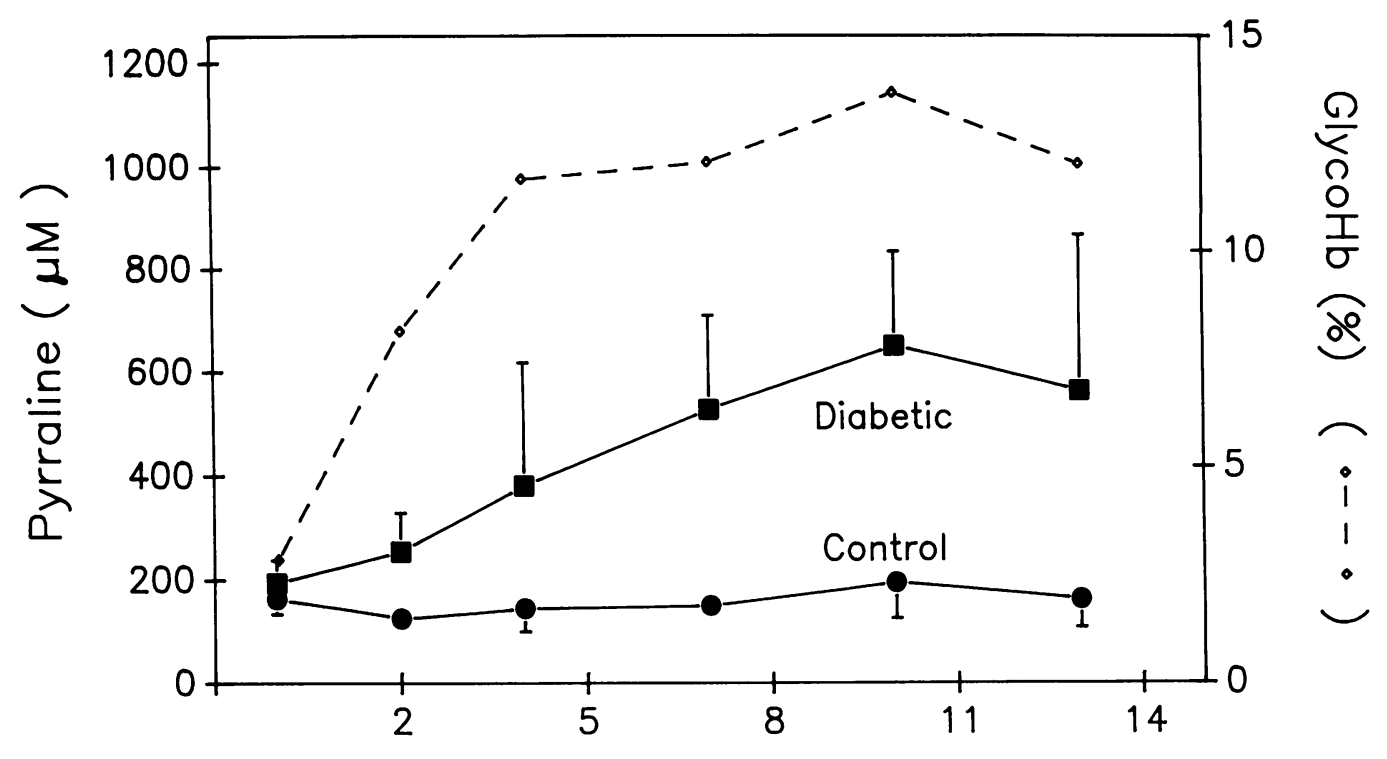

Figure 6. Temporal relationship of plasma pyrraline values (mean $\pm \mathrm{SD}$ ) in Sprague-Dawley rats with streptozotocin diabetes induced at 0 week. Control animals received $0.1 \mathrm{M}$ citrate buffer ( $\mathrm{pH} 4.0)$ injections only. The mean level of glycohemoglobin is shown for diabetic rats. Llysyl pyrraline was used as a standard.

Quantitation of pyrraline immunoreactivity in plasma of diabetic rats and humans. Pyrraline immunoreactivity was quantitated in plasma from streptozotocin diabetic rats and from diabetic humans. After the onset of diabetes in rats, a rapid increase in the level of glycosylated hemoglobin was observed which plateaued at 4 wk (Fig. 6). A slower but steady increase in pyrraline immunoreactivity developed in the plasma that reached plateau levels 3 wk later. This slow increase is compatible with the fact that glycated proteins are necessary precursors to pyrraline protein conjugates.

Rat plasma pyrraline immunoreactivity at $10 \mathrm{wk}$ was compared with that of randomly obtained plasma specimens from diabetic individuals (Fig. 7). Mean levels of glycohemoglobin in rat at that time was $13.7 \pm 2.0 \%$, similar overall to that of the diabetic individuals $(11.7 \pm 2.9 \%)$. However, whereas pyrraline immunoreactivity in nondiabetic rat and human plasma was overall similar $(194.2 \pm 69.9 \mu \mathrm{M}$ and $115.5 \pm 36.5 \mu \mathrm{M})$, mean pyrraline immunoreactivity was three times higher in diabetic rat plasma than in plasma from diabetic individuals $(627.4 \pm 189.0$ vs. $211.8 \pm 103.4 \mu \mathrm{M})$. Furthermore, whereas mean values were significantly elevated in diabetes $(P<0.001$ and $P<0.01$, respectively), definitive overlap between normal and diabetic values was present in human plasma, suggesting that the human is better protected against hyperglycemia than the rat at overall equivalent level of glycohemoglobin.

Immunocytochemical detection of pyrraline immunoreactivity in tissue sections from diabetic subjects. Presence of pyrraline epitopes in relationship to diabetic complications and aging was sought in tissue sections obtained at autopsy from young, middle-aged, and old nondiabetic subjects, and in middle-aged subjects who died of severe complications. Representative findings frequently observed in age- and disease-matched subjects are presented below.

Almost no pyrraline immunoreactivity was observed in very young, i.e., 22-d old renal glomeruli or tubuli (Fig. $8 a$ ). However, pyrraline immunoreactivity was already apparent in adolescence and was associated with peritubular and extracellular matrix. The staining pattern was overall similar to that of a 36-yr old normal kidney (Fig. 7). Glomerular and tubular structures were generally spared as long as these were free of sclerotic basement membranes. A frequent finding in diabetic kidneys with advanced Kimmelstiel-Wilson glomerulosclerosis was a crescent-shaped staining pattern which occasionally occupied the entire area of terminally sclerosed glomeruli (Fig.
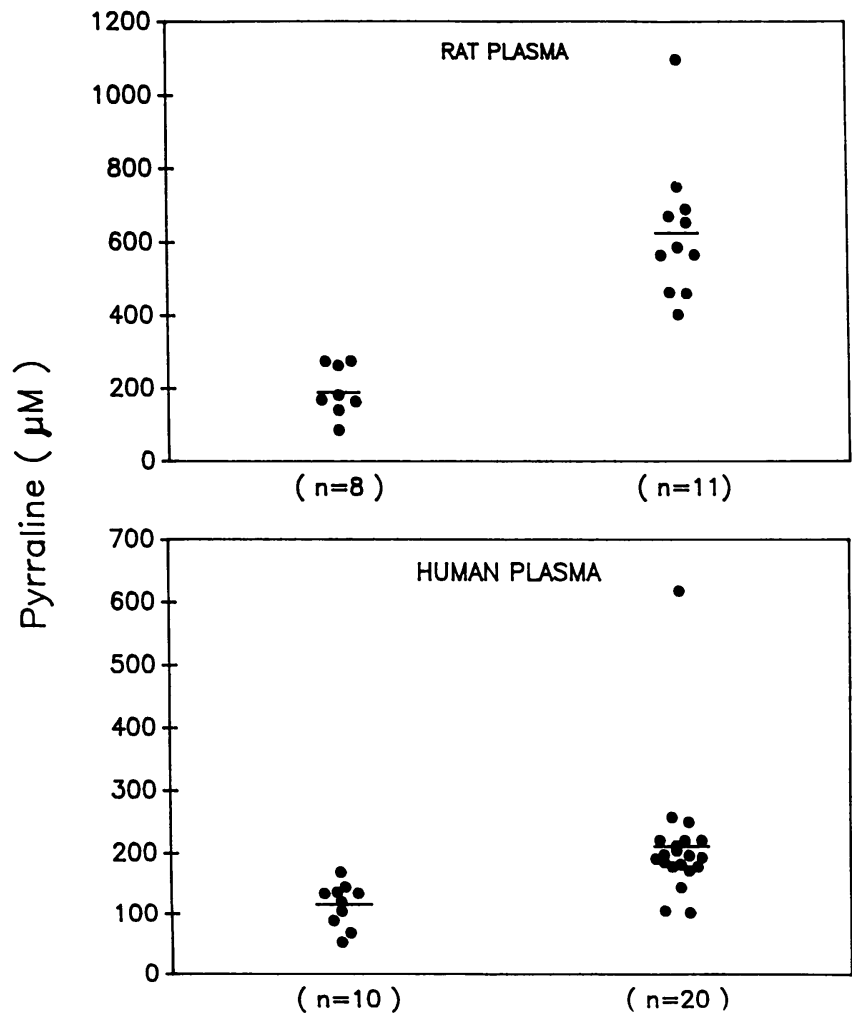

Figure 7. Comparison of individual pyrraline values in rats with 10 weeks of streptozotocin diabetes and in diabetic humans. Mean level was elevated in diabetic rats versus controls $(P<0.001)$ and in diabetic versus nondiabetic controls $(P<0.01)$. Mean level of glycohemoglobin was $13.7 \pm 2.0 \%$ in rats and $11: 7 \pm 2.9 \%$ in humans. L-lysyl pyrraline was used to standardize the ELISA. 

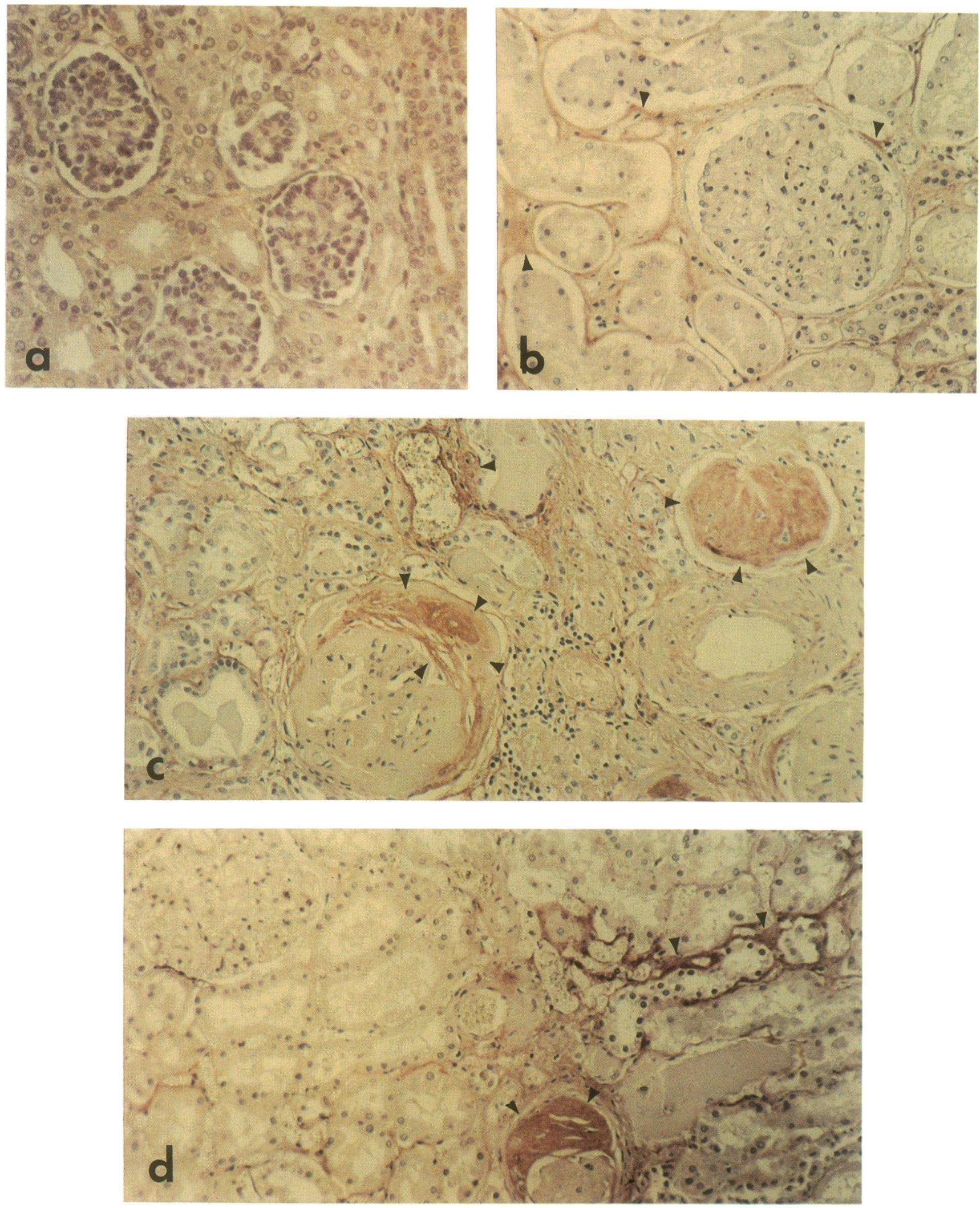

Figure 8. Light photomicrographs of paraffin-embedded renal tissue sections showing immunohistochemical localization of pyrraline hapten by immunoperoxidase. The brown peroxidase reaction product is localized at antigenic sites. The tissue was counterstained with hematoxylin. $(a)$ No staining is seen in glomerular, tubular, and extracellular areas of an infant kidney $(\times 400)$. (b) Pyrraline immunoreactivity is seen in interstitium but not in glomerular and tubular regions of a 36-yr old normal kidney $(\times 400)$. (c) Intense pyrraline immunoreactivity in sclerosed and obliterated glomeruli and sclerosed insterstitium of a 40 -yr old diabetic kidney with end stage renal disease. A pyelonephritic component is present $(\times 400) .(d)$ Crescent shaped pyrraline immunoreactivity in obliterated glomerulus from an 87 -yr old nondiabetic kidney (arrow). Intense staining is present in thickened peritubular matrix but absent in a normal glomerulus (top left $)(\times 400)$. 
$8 c$, arrows). A similar crescent-shaped staining pattern was. seen in sclerosed glomeruli of an 87-yr old nondiabetic kidney, but staining was absent in normal glomeruli (Fig. $8 d$ ). Intense staining was also associated with thickened tubular extracellu- lar matrix both in middle-aged diabetic and old nondiabetic kidney.

Particularly interesting findings were made in renal arteries from diabetic kidneys with severe arteriolosclerosis (Fig. $9 a$ ).
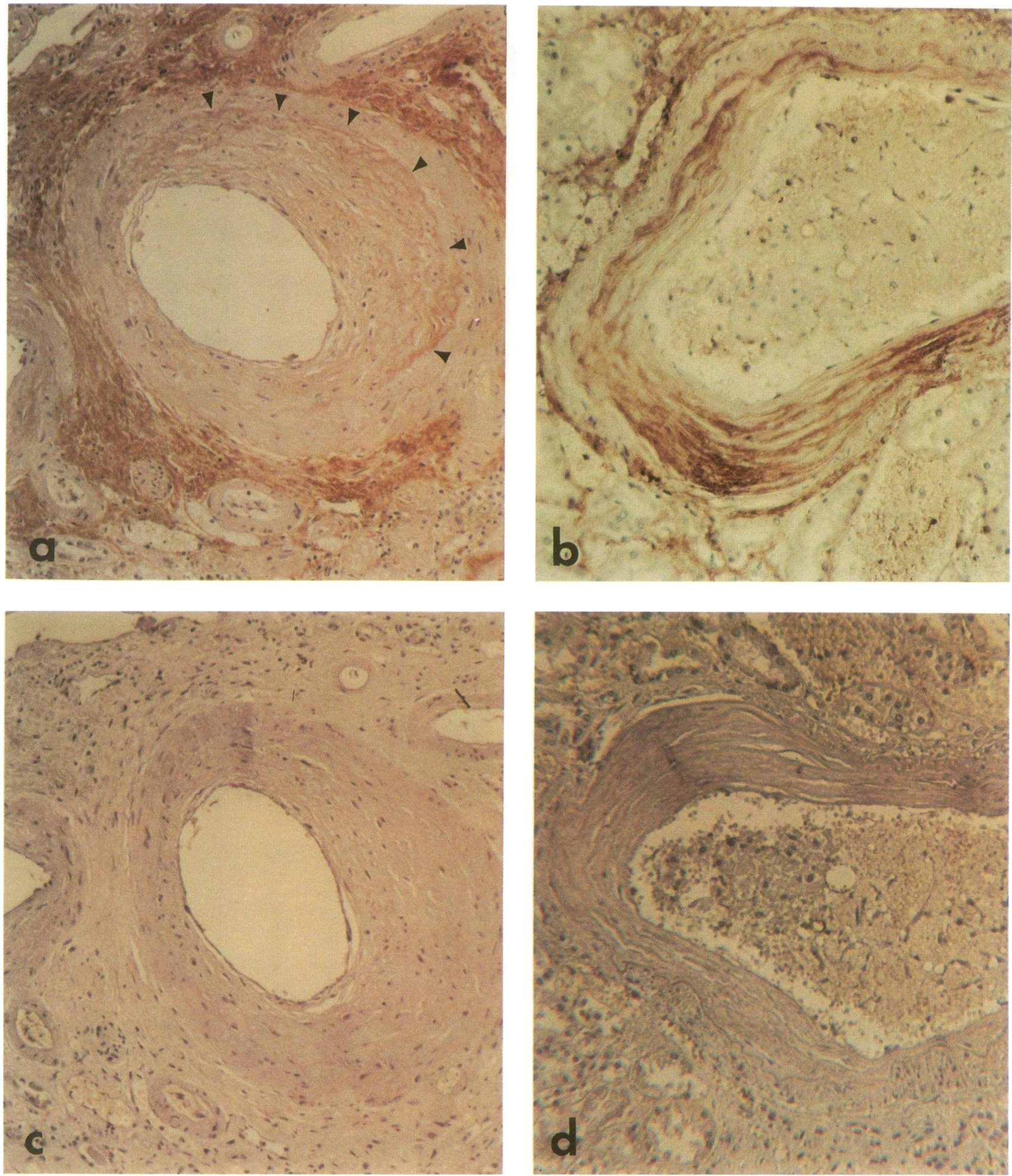

Figure 9. Pyrraline immunoreactivity in renal arterioles. (a) Intense staining in perivascular sclerosed regions of a 40-yr old diabetic kidney. Note the pyrraline immunoreactivity corresponding to the sclerosed arteriolar area (arrows) $(\times 175)$. (b) Intense pyrraline immunoreactivity in the arteriolar wall of an $87-\mathrm{yr}$ old nondiabetic kidney $(\times 175)$. $(c-d)$ Pyrraline immunoreactivity was completely blocked by preincubation of the monoclonal antibody with the free hapten caproyl pyrraline $(\times 175)$. 
Pyrraline immunoreactivity appeared to match precisely the contour of the sclerotic area (Fig. $9 a$ ). Intense staining was also present in the perivascular sclerotic matrix (Fig. $9 a$ ) and in the arterial wall of an apparently healthy mid-size artery of the old kidney (Fig. 9 b). The fact that the staining was highly specific for pyrraline is demonstrated by the ability of the free hapten to completely block binding of the monoclonal antibody and the subsequent staining by the secondary antibody (Fig. 9, $c$ and $d$ ). The lowest free hapten (caproyl pyrraline) concentration at which complete blocking was obtained was $25 \mu \mathrm{M}$, i.e., the identical concentration used for complete inhibition in the ELISA.

Marked pyrraline immunoreactivity was also seen in thickened bronchial basement membrane from a diabetic lung (Fig. $10 a$ ) and was diffusely present in collagenous tissue in trachea (Fig. $10 b$ ), skin (Fig. $10 c$ ), and pancreas (not shown). Basement membranes of brain microvessels were also positive for pyrraline (Fig. $10 d$ ). Age or presence of diabetes did not affect
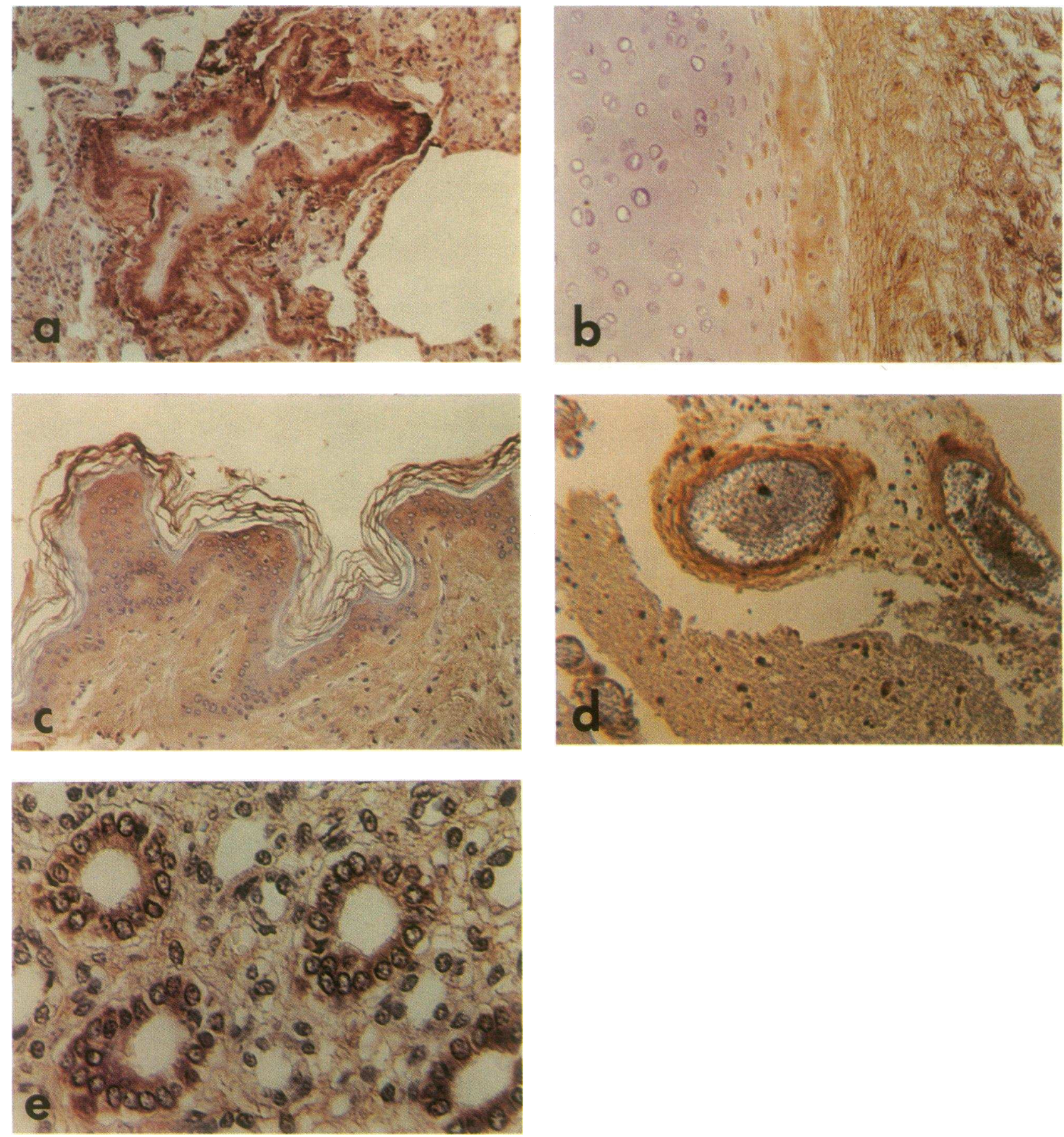

Figure 10. $(a-d)$ Pyrraline immunoreactivity in extrarenal tissues from a middle-aged diabetic individual. $(a)$ bronchioles $(\times 175)$; $(b)$ tracheal cartilage and connective tissue $(\times 175)$; $(c)$ skin $(\times 175)$; and $(d)$ brain microvessels $(\times 400)$. The overall staining intensity was similar in tissues from nondiabetic individuals (not shown). (e) Pyrraline immunoreactivity in collecting tubules of an infant receiving intravenous hyperalimentation before death $(\times 400)$. 
substantially these staining patterns. Overall, no major differences in pyrraline immunoreactivity were seen in coronary arteries, aortas, or nerves from middle-aged and elderly individuals with or without diabetes, although patchy pyrraline spots were occasionally seen in some aortas (not shown). Curiously, intense staining was observed in renal tubular cells from an infant who died after intravenous hyperalimentation (Fig. $10 e$ ).

\section{Discussion}

The purpose of this study was the development of monoclonal antibodies to a major advanced glycosylation/Maillard product in order to allow the in situ localization of advanced glycosylation end products in tissues from diabetic and aging individuals. Three observations suggest that the epitope found in histological sections is indeed related to pyrraline. First, the antibody recognized pyrraline that formed with time in glucose and 3-deoxyglucosone incubated human serum albumin in a dose-dependent manner, especially from its immediate precursor, 3-deoxyglucosone. Second, increased antibody affinity to rat and human plasma proteins was noted as a function of diabetes as reflected by elevated glycohemoglobin levels. Third, and above all, the histochemical stain could be completely blocked by preincubating the monoclonal antibody with low concentrations of the free hapten caproyl pyrraline for which antibody affinity is $\sim 8.5 \times 10^{8} \mathrm{M}$. Thus, the data presented above provide strong support for the in situ formation of pyrraline as a consequence of advanced glycosylation in vivo.

The preferential formation of pyrraline in the extracellular matrix of renal and other tissues is not unexpected. Because overall pyrraline formation rate is slow, it is likely to be detected mainly in proteins with a slow turnover such as those of the extracellular matrix. This may also explain why the extracellular matrix of young kidneys react to the pyrraline antibody with an overall staining pattern similar to that of a middle-aged normal kidney. Thus, one can conclude that a certain degree of blockage of lysine residues by pyrraline may have little effect on the turnover of the extracellular matrix under physiological conditions. In contrast, the intense staining seen in thickened and sclerosed areas of diabetic and old kidneys suggests that pyrraline formation and sclerosis may be related processes.

A major question is how the focal formation of pyrraline in sclerosed glomeruli and renal arteries should be interpreted. Obviously, if the advanced glycosylation reaction was only dependent on ambient glucose concentration, one would expect diffuse formation of pyrraline. However, a number of mechanisms may explain why the advanced Maillard reaction as reflected by pyrraline formation may not proceed in all tissue regions at the same rate. First, pyrraline-poor tissue regions may be metabolically more active than others, and enzymes like the 2-oxoreductase have been found to use 3-deoxyglucosone as substrate, thus preventing biochemical consequences of the advanced Maillard reaction such as cross-linking $(17,18)$. Second, the turnover rate of extracellular matrix poor in pyrraline may be higher due to focal differences in cellular composition. For example, it appears from Fig. 9, $a$ and $b$, that cell density is generally lower in pyrraline-rich that in pyrralinepoor areas. Third, pyrraline-rich regions may result from the selective synthesis of extracellular matrix proteins that favor pyrraline synthesis or accessibility to the antibody. Work by a number of investigators suggests that hyperglycemia in diabetes may lead to increased synthesis of extracellular matrix proteins (19). In the diabetic kidney, for example, synthesis of type IV collagen, laminin fibronectin is upregulated $(20,21)$.

In arteriolosclerosis, on the other hand, there is a massive increase in extracellular matrix deposition as well as varying degree of hyalinization. Thus, some of these newly synthesized proteins could be preferential targets for the formation or detection of antibody binding to a pyrraline epitope. Future studies using double-labelling technique may shed light on the question of whether pyrraline formation is specific to particular proteins of the extracellular matrix. In that regard, the increased affinity for deaminated lysyl-pyrraline, i.e., norlysylpyrraline (Fig. 3) suggests that the antibody may be recognizing an altered pyrraline structure in the tissue.

The unexpected finding of pyrraline immunoreactivity in tubular cells of a kidney from an infant who died after a period of hyperalimention raises the question of whether this treatment modality catalyzes specifically the advanced Maillard reaction and whether tubular cells have reabsorbed pyrraline modified plasma proteins.

In summary, the availability of a monoclonal antibody to pyrraline revealed a strong association between sclerosis and pyrraline immunoreactivity in renal tissues from diabetic and aging individuals, providing further support to the concept that advanced glycosylation may decrease the reversibility of sclerotic lesions. However, at this point the question of whether pyrraline is simply an epiphenomenon or whether it has a direct pathogenetic role in the sclerotic process remains to be answered. Its ability to form cross-links by reacting with itself (22) would support the latter possibility.

\section{Acknowledgments}

We thank Dr. Charlotte Kaetzel, Ms. Janet Robinson, and Candace Roskoph for teaching us how to make monoclonal antibodies. We thank Dr. George Perry, Mr. John Fogarty and Ms. Mary Abuhl for assistance with immunohistochemical studies and Dr. Sunitha Grandhee for synthesizing $\epsilon$-amino caproyl pyrraline.

This work was supported by grant AG 05601 from the National Institute on Aging, grant EY 07099 from the National Eye Institute, and a grant from the Juvenile Diabetes Foundation International.

\section{References}

1. Baynes, T. W., and V. M. Monnier. 1989. The Maillard reaction in aging, diabetes and nutrition. Prog. Clin. Biol. Res. 304:1-410.

2. Dunn, J. A., D. R. McCance, S. R. Thorpe, T. J. Lyons, and J. W. Baynes. 1991. Oxidation of glycated proteins: age-dependent accumulation of $\mathrm{N}^{\epsilon}$-(carboxymethyl)-lysine and $\mathrm{N}^{\epsilon}$-(carboxy-methyl)-hydroxylysine in human skin collagen. Biochemistry. 30:1205-1210.

3. Dunn, J. A., J. S. Patrick, R. S. Thorpe, and J. W. Baynes. 1989. Oxidation of glycated proteins: age-dependent accumulation of $\mathrm{N}^{\mathrm{c}}$-(carboxymethyl)-lysine in lens proteins. Biochemistry. 28:9464-9468.

4. Sell, D. R., and V. M. Monnier. 1989. Structure elucidation of a senescence crosslink from aging human extracellular matrix. J. Biol. Chem. 264:2159721602.

5. Sell, D. R., and V. M. Monnier. 1990. End-stage renal disease and diabetes catalyze the formation of a pentose-derived crosslink from aging human collagen. J. Clin. Invest. 85:380-384.

6. Oimomi, M., Y. Kitamura, S. Nishimoto, S. Mastsumoto, H. Hatanaka, and S. Baba. 1986. A study of the age-related acceleration of glycation of tissue proteins in rats. J. Gerontol. 41:695-698.

7. Oimomi, M., Y. Maeda, F. Hata, K. Yoshiaki, S. Mausumoto, S. Baba, T. Iga, and M. Yamamoto. 1989. Glycation of cataractous lens in non-diabetic senile subjects and in diabetic patients. Exp. Eye Res. 46:415-420.

8. Njoroge, F. G., L. M. Sayre, and V. M. Monnier. 1987. Detection of D-glucose-derived pyrrole compounds during Maillard reaction under physiological conditions. Carbohydr. Res. 167:211-220.

9. Njoroge, F. G., A. A. Fernandes, and V. M. Monnier. 1987. 3-(D-Erythrotrihydroxy-propyl)-1-neopentyl pyrrole-2-carboxaldehyde, a novel nonenzymatic browning product of glucose. J. Carbohydr. Chem. 6:553-568. 
10. Nakayama, T., F. Hayase, and H. Kato. 1980. Formation of E-(2-Formyl5-hydroxymethyl-pyrrol-1-y $)$-L-norleucine in the Maillard reaction between Dglucose and L-lysine. Agric. Biol. Chem. 44:1201-1208.

11. Jurch, G. R., and J. H. Tatum. 1970. Degradation of D-glucose with acetic acid and methylamine. Carbohydr. Res. 15:233-239.

12. Hayase, F., R. H. Nagaraj, S. Miyata, F. G. Njororge, and V. M. Monnier 1989. Aging of proteins: immunological detection of glucose-derived pyrrole formed during Maillard reaction in vivo. J. Biol. Chem. 264:3758-3764.

13. Khadem, H. E., D. Horton, M. H. Meshreki, and M. A. Nashed. 1971 New route for the synthesis of 3-deoxyaldose-2-uloses. Carbohydr. Res. 17:183192.

14. Staros, J. V., R. W. Wright, and D. M. Swingle. 1986. Enhancement by $\mathrm{N}$-hydroxysulfosuccinimide of water-soluble carbodimide-mediated coupling reactions. Anal. Biochem. 156:220-222.

15. Schulman, M., C. D. Wilde, and G. Kohler. 1978. A better cell line for making hybridomas secreting specific antibodies. Nature (Lond.). 276:269-270.

16. Kaetzel, C. S., I. H. Mather, G. Bruder, and P. J. Madara. 1984. Characterization of a monoclonal antibody to bovine xanthine oxidase. Biochem. J. 219:917-925.
17. Shin, D. B., F. Hayase, and H. Kato. 1988. Polymerization of proteins caused by the reaction with sugars and the formation of 3-deoxyglucosone under physiological conditions. Agric. Biol. Chem. 52:1451-1458.

18. Hayase, F., Z.-Q. Liang, T. Shinoda, N. Van Chuyen, H. S. Shin, T. Nishimura, and H. Kato. 1991. Enzymatic metabolism of Maillard intermediates. Amino Acids. 1:1-158.

19. Cagliero, E., M. Maiello, D. Boeri, S. Roy, and M. Lorenzi. 1988. Increased expression of basement membrane components in human endothelial cells cultured in high glucose. J. Clin. Invest. 82:735-738.

20. Roy, S., R. Sala, E. Cagliero, and M. Lorenzi. 1990. Over-expression of fibronectin induced by diabetes or high glucose: phenomenon with memory. Proc. Natl. Acad. Sci. (USA). 87:404-408.

21. Falk, R. J., J. I. Scheinman, S. M. Mauer, and A. F. Michael. 1983. Polyantigenic expansion of basement membrane constituents in diabetic nephropathy. Diabetes. 32:34-39.

22. Olsson, K., P.-A. Pernemalm, T. Popoff, and O. Theander. 1977. Formation of aromatic compounds from carbohydrates. V. Reaction of D-glucose and methylamine in slightly acidic, aqueous solution. Acta Chem. Scand. B31:469474. 